\title{
The evidence for brain injury in whiplash injuries
}

\author{
Prof. Michael P. Alexander, M.D*
}

\section{The problem}

The mechanical forces of sudden acceleration/deceleration of the head and the neck producing soft tissue injury to the neck are considered throughout this book. The goal of this chapter is to review the evidence that brain damage can occur in injuries that produce whiplash. The specific clinical and scientific question in whiplash is usually posed as follows: $\mathrm{C}$ an the purely inertial forces in whiplash injury cause inertial brain damage? This question is frequently phrased as though the whiplash case is somehow distinctive, but it is essentially the same question raised in people who have had some closed head injury with or without neck injury. The clinical phenomena are the same: brief loss of consciousness followed by brief confusion or, alternatively, dazed, conscious moments followed by confusion. Pure whiplash injury implies no, or only minimal, head contact, but many patients also have head contact against a head rest or even the steering wheel or windshield. What actually distinguishes whiplash from mild closed head injury is the relative severity of the neck injury and the head injury. A s patients with whiplash, with or without head contact, are rarely unconscious, they would fit in all schemes for classification of concussion as mild or grade 1 or possibly 2 , if they have any concussion at all $(1,2)$. That is, if there is brain injury in some patients with whiplash, it falls at the mildest end of the concussion spectrum - essentially by definition.

This review will proceed as follows:

1. Do patients who have had whiplash have cognitive symptoms? What is the frequency?

2. Do examination, laboratory studies or neuropsychological tests demonstrate abnormalities consistent with cognitive symptoms and brain injury?

3. A re there experimental models or pathological data to support possible brain injury?

4. A re there alternative explanations for cognitive impairment that do not require a brain injury mechanism?

5. How does the literature on concussion inform us regarding whiplash?

6. If there are alternative explanations, are they powerful enough to eliminate brain injury explanations in all or most patients with cognitive symptoms?

\section{Symptoms of possible brain injury}

Early symptoms suggesting brain injury after whiplash are common (3-7). Prospective studies of pure whiplash report that impaired concentration and forgetfulness are frequent $(>25 \%)$. $M$ ental fatigue, impaired sleep, sensory sensitivities and dizzness are also common. Headache is almost universal but is often inseparable from neck pain and stiffness. Symptoms of poor concentration, poor memory and mental slowness remain frequent for 1-3 months. In prospective studies, these cognitive symptoms decline to $10-20 \%$ by one year.

There are several clinical series that report very high $(>50 \%)$ cognitive symptoms after one year, but these series are very selective (8-10). They are assembled from forensic and specialty clinics. They testify to the high frequency of cognitive complaints in the persistent patients with residuals of brain injury. There are no claims that all or even most patients with whiplash have concussion, but it is possible that idiosyncrasies of head position, rotational movement or some other unknown factor could lead to concussion in a portion of patients with whiplash. These would presumably be the ones with persistent symptoms. By comparison, in large series of concussion the early cognitive symptoms are the same, but the frequency is considerably higher. A t one year there remains, however, about $10-20 \%$ with persistent cognitive symptoms (11). For concussion, there are also clinical series with virtually universal cognitive complaints, but with the same reservations about interpretation.

\section{Signs and supporting evidence of brain injury}

Examination of whiplash patients with cognitive complaints is not very helpful. Routine neurological examination is normal (excluding signs related to the neck injury at times). Clinical mental status evaluation rarely suggests any definite abnormality. Structural imaging of the brain is normal (other than very rare subdural hematoma reports) $(12,13)$. SPECT in pure whiplash has usually (14), but not invariably (15), been reported as normal. Even for patients with classic concussion when SPECT is often abnormal, interpretation has been controversial (see below).

The major supporting evidence for brain injury after whiplash, as in classic concussion, comes from neuropsychological testing. Neuropsychological tests in symptomatic patients consistently demonstrate deficits. Consider prospec-

\footnotetext{
*H arvard M edical School; B oston U niversity, Boston, M assachusetts, U SA

Correspondence: Dr M ichael A lexander, B eth Israel Deaconess, East 330 Brookline A venue. c/o Dr G alaburda, KS-2 Boston, M assachusetts 02215, U SA. Telephone 617-667-4079, fax 617-697-7981
} 
tive, acute phase (<one month) studies: RADANOV AND COW ORKERS reported a large series of patients tested at one week and 6-7 months after whiplash injury (16). $\mathrm{N}$ europsychological assessment was focused on sustained attention and rate of information processing. At the acute assessment, there was a deficit in both the PA SAT (paced auditory serial addition test - a commonly used tool to measure processing speed) and Trails B tasks. By 6 months the impairments had cleared. ETTLIN ET A L. compared 21 acute whiplash patients to matched controls (3). No specific group differences were significant on a large battery of tests, but comparison of each patient against a control suggested that whiplash patients were more likely to have lower performance on tests of attention and executive function. KARLSBORG ET AL. reported on neuropsychological findings in 39 patients with whiplash tested within one month of injury (6). Three patients had mild deficits in attention, all cleared by six months later.

A sample of studies of neuropsychological findings in chronically symptomatic whiplash patients reveals cognitive deficits. KISCHKA ET AL. reported on detailed testing in a case matched series of 52 patients with chronic whiplash (10). Of 27 neuropsychological tests, the whiplash group had an excess number of impaired performance on 5 tests, 4 considered attentional and one considered memory. KESSELS ET AL. compared 26 chronic whiplash patients to a normal control group (17). The patient group had decreased average PA SAT results. TAYLOR ET AL. compared 18 chronic patients to 10 patients recovered from severe brain injury (TBI) and matched controls (18). The whiplash group was mildly but significantly worse on a difficult test of memory that is very sensitive to suppression of interference. SCHM AND ET AL. used a similar technique - comparing chronic patients to a group well recovered from severe $\mathrm{TBI}$ and a group of normal controls (19). The overall group differences showed that the whiplash group was $\sim$ impaired than the severe $T B I$ group on tests of memory and attention. RADANOV ET AL. reported impaired divided attention and working memory in a group of 21 chronic whiplash patients (14). HENRY ET A L. claimed impaired executive functions in a group of 32 patients with chronic symptoms after whiplash (8). The authors describe abnormalities in qEEG in all 32 patients, asserting that the physiologic findings corroborate the neuropsychological findings although the methodology and interpretation of qEEG remains highly suspect. M RI was normal in all patients. KESSELS ET AL. recently performed a meta-analysis of a large number of studies (20). O nly eight of 25 reports were statistically robust enough to interpret. The meta-analysis confirmed that whiplash patients have impairments in memory and attention when compared to controls.

\section{Pathological evidence for brain injury}

The single outstanding experimental model that supports possible brain injury in whiplash is the pure inertial injury of GeNNARELLI ET AL. using small, nonhuman primates (21). The animals' heads were fixed, and the injury was delivered through purely acceleration/deceleration force. By varying the direction and rotation of head movement and the force of deceleration the authors could produce the entire spectrum of diffuse axonal injury (DAI). Typical histopathology of DA I was observed in all animals with unconsciousness greater than a few minutes. The animals who regained consciousness promptly (perhaps analogous to whiplash) did not have evidence for DA I although presumably more specific analysis of axonal functional integrity might have demonstrated some impairment. A ssessment of behavioral or cognitive effects of the mildest injuries was obviously limited, but by observation recovery appeared quick and complete. Pertinent to this review, when head movement was oblique (presumably meaning generating rotation) DA I was more severe than when the same deceleration forces were produced in the sagittal plane. This might be one of the idiosyncratic factors of a whiplash injury that raises the risk of brain injury during an accident.

There is, for obvious reasons, very limited pathological information on whiplash and concussion in humans. The single study, cited by everyone who reviews this topic, was by O PPENHEIMER in 1968 (22). A lthough several patients with mild TBI are mentioned, a complete clinical description is only available for one. This patient had loss of consciousness and amnesia for over 30 minutes. A utopsy demonstrated mild, but unequivocal, DAI. By clinical variables, this injury, while still "mild", is considerably more significant than seen in the usual whiplash patient.

\section{Summary of evidence for brain injury}

Patients with whiplash have a high frequency of cognitive symptoms in the first weeks after injury. By one year later only a small fraction of patients still have symptoms, but cognitive symptoms are very frequent in this group. When tested in either the acute or chronic (highly selected population) phases, neuropsychological impairments are usually noted on information processing capacity and in attention. W hile there is no evidence for brain injury at the level of M RI, regional abnormalities on SPECT may be seen. There is an experimental model for $\mathrm{TBI}$ that at least raises the possibility that purely inertial injuries may cause brain damage in humans.

There is a potential logical fallacy: if TBI causes certain symptoms and is associated with particular SPECT abnormalities, must the same symptoms and similar SPECT findings in whiplash in evitably imply T BI? "If $A$, then $B$ ", rarely means "if $B$, then $A$ ", regardless of respect for parsimony. It is an obligation to determine if there are other explanations besides brain injury that account for the profile described above. Thus, each facet of the argument requires reexamination.

\section{Symptoms revisited}

The common cognitive complaints are forgetfulness, poor concentration, poor memory and fatigue, in addition to various somatic complaints such as headache, neck pain, diziness etc. There are three limitations to acceptance of the cognitive symptoms as supportive of brain injury.

First, further review of the same reports describing cognitive symptoms reveals an equally impressive array of psychological complaints. In ETTLIN ET AL., 18 of 21 acute patients had insomnia, and nine were frankly depressed (3). In RA DA N OV ET A L. anxiety and insomnia were each present in over 40\% (16). The mild neuropsychological abnormalities presented at one month, cleared by six months in patients who were asymptomatic, but were persistent, albeit very mild, in patients with persistent pain. The same group (1994 JN N P) reported two 
aspects of one year follow-up of whiplash $(4,23)$. Cognitive recovery was best predicted by initial severity of pain. Cognitive complaints were generated by somatic problems such as pain, poor sleep and the "initial \{psychological \} reaction to injury" (4). A $n$ analysis of 29 acute patients demonstrated a strong association of cognitive symptoms with pain.

Cognitive symptoms in chronic whiplash patients appear as ambiguous as in acute patients. Although TAYLOR ET AL. demonstrated modest decline in a complex memory test in 18 chronic whiplash patients, the severity of pain appeared to account for the deficits (18). Data are actually available on only 15 patients as three were frankly malingering. The large series $(\mathrm{N}=108)$ of chronic patients reported by SCH M A N D ET AL also ostensibly showed cognitive impairments, but the most "impaired" patients had a very high incidence of malingering or at least of volitional under performance (19). RADANOV ET AL in a study of a small group of chronic whiplash patients, demonstrated that the deficits in divided attention showed no correlation with regional PET findings (14). A ttention was strongly correlated with pain intensity with high depression and anxiety scores. Thus, cognitive symptoms seem to be directly related to pain intensity and secondary to psychological factors, including depression, anxiety, and malingering.

A second reason for hesitation in attribution of cognitive symptoms to brain injury lies in the symptom profile. The profile has no specificity. Patients with unequivocal concussion have certain symptoms so commonly that they are reasonably considered a phenomenological syndrome, the postconcussion syndrome (PCS): headache, diziness, sleep disorders, poor concentration, fatigue, forgetfulness etc. (II). The diagnostic specificity of that symptom cluster is, however, extremely poor. The same cognitive symptoms are reported by patients without any clinical suggestion of brain trauma who have depression, anxiety and chronic pain, and these are all problems of the chronic whiplash patient. There is symptomatic overlap with post-traumatic stress disorder (24). The same cognitive symptoms have been reported in chronic fatigue syndrome (25) and fibromyalgia (26), and the latter is frequently a concurrent diagnosis in whiplash (27). Patients with outstanding injuryrelated litigation (28), again without any assertion of brain injury, report similar symptoms. Thus, cognitive symptoms are greatly over-determined in whiplash patients, and there are several other possible explanations for cognitive symptoms that have greater validity than a brain injury explanation.

A third reason for caution is the uncertainty of the effect of patient expectations. The base rate of these symptoms is quite high (29). A substantial portion of patients screened for PCS symptoms at routine medical visits endorse current or recent symptoms. N ormal subjects markedly underestimate this base rate, even when they acknowledge the personal experience of the symptoms (30). N ormal subjects, at least in the US, also "expect" the symptoms to be present in people who have had a concussion. This combination of findings could mean that patients will over-attribute symptoms to a recent event that they "expect" to cause symptoms. Several studies from Lithuania have demonstrated that in the absence of "expectations", symptoms are still present but that they rapidly attenuate (31). Thus, expectations can be transmuted to a syndrome. W ell meaning "medicalization" - referral to specialists, imag- ing studies and frank discussions of possible medical implications - inadvertently prolongs symptoms $(23,32)$. Then failure to find a "cause" may exacerbate anxiety and on and on.

Recall: because concussion frequently produces certain symptoms does not mean that those symptoms, months and years after an injury of modest significance, are due to the injury.

\section{SPECT revisited}

Only one study has made a specific claim about SPECT abnormality in chronic whiplash (15). O TTE ET A L. observed bilateral parietal hypoperfusion in a small group of chronic whiplash patients. This claim was investigated by BICIK ET AL. by performing FDG-PET, MRI and SPECT in a series of chronic whiplash patients (33). The authors were able to demonstrate that the biparietal finding was an artifact of cortical thickness and angulation.

The original premise of this review was that brain injury due to whiplash, if it occurred at all, must be at the mildest end of the spectrum of concussion because loss of consciousness is rare, amnesia is brief or nonexistent, and structural imaging does not reveal contusions. If that premise is correct, then review of SPECT in concussion would have relevance for the whiplash question. There is a large literature on SPECT in mild TBI.

In a small series of patients studied with SPECT within two days of concussion, most had patchy, primarily frontal hypoperfusion (34). No follow-up was reported. In a large series of concussion patients scanned within one month ( $75 \%$ within one week), SPECT was abnormal in 73 of 136 patients (35). The pattern was multi-focal cortical hypoperfusion; $60 \%$ of abnormalities were in frontal lobes. This study had excellent SPECT and clinical follow-up. Symptoms, neuropsychological deficits and SPECT abnormalities all decreased over one year. A t one year, only 12 patients with initially abnormal SPECT still had abnormal SPECT; $78 \%$ of abnormalities were frontal. Of the total population of 136 , only 11 (8.1\%) were still symptomatic; nine of those had abnormal SPECT. There were three patients with abnormal SPECT but no clinical symptoms. The authors noted that clinical improvement frequently preceded SPECT normalization.

Several studies of selected TBI patients, often with mixed severity, scanned in the chronic phase have shown a high rate of abnormal scans. G RAY ET A L. reported that 12 of 20 mild T BI patients had abnormal SPECT more than six months after injury (36). ICHISE ET AL. reported that eight of 15 chronic mild TBI patients had abnormal SPECT (37). M ost abnormalities were focal areas of hypoperfusion in frontal or temporal lobes. They proposed that a general decrease in the perfusion ratios between frontal regions and posterior brain would identify the injury although only four of 15 actually had a clearly abnormal A P ratio.

KANT ET AL. reported 43 patients with mild TBI referred to a specialty clinic because of persistent "neuropsychiatric difficulties" at a mean of 16 months after injury (38). The BDI scores were markedly elevated $(75 \%>17$; mean 25$)$. SPECT demonstrated focal abnormality in $23(53 \%)$ patients - frontal $(54 \%)$, temporal $(24 \%)$ or basal gan glia $(14 \%)$. There were no significant differences between the groups with and without 
SPECT abnormalities on any neuropsychological measure or on the BDI. The authors concluded that the abnormal SPECT identified brain damage that, in turn, was responsible for "some of the neuropsychiatric symptoms".

BICIK ET AL. (33) reported SPECT findings in 13 patients with persistent pain and cognitive symptoms at a mean of 27 months after injury (partly reviewed above). The SPECT studies were co-registered with FDG-PET and structural M RI. No individual patient bad significant regional abnormalities, but in group analyses, both PET and SPECT demonstrated abnormalities in frontal and subcortical structures. The only significant correlation was between FDG-PET hypoperfusion in frontal regions $(r=-0.71)$ and depression.

Comparison of findings in whiplash and concussion to findings in other disorders is illuminating. There are abundant reports of functional imaging in psychiatric disorders. A few examples: IIKADA ET AL. demonstrated a correlation between reduced frontal perfusion and severity of depression with SPECT (39). ITO ET AL. demonstrated significant hypoperfusion in prefrontal and anterior temporal regions in depressed patients (40). They concluded that these regions of reduced function due to depression might underlie the attentional, cognitive and emotional abnormalities common in depression. This is, of course, the opposite direction of causation proposed by KANT ET AL. (38) and KISCHKA ET AL. (10). Two reviews of functional imaging in depression $(41,42)$ have concluded that depression is associated with consistent abnormalities in frontal and temporal regions. G oo DW IN stated that "reductions in frontal areas may be more likely in patients with impoverished mental states", summarizing a literature that consistently shows decreased attention and slow processing in depression (41). A similar distinction among depressed patients had been previously suggested by DOLAN ET AL. among others (43). There is greater PET hypoperfusion in depressed patients with cognitive impairment (due to depression) than there is in patients with depression but intact cognitive performance. LUCEY ET AL. found numerous abnormalities on SPECT in 46 patients with anxiety disorders (44). The strongest correlations (all negative) were between depression scores or PT SD severity and caudate perfusion.

\section{Pathology revisited}

Returning to the experimental model in primates, within the limitations of assessment of cognition in non-human primates, the investigators emphasized that the severity and duration of behavioral abnormalities strongly paralleled the extent of DA I pathology (21). A s in humans, depth of coma, duration of coma, and eventual outcome are all strongly correlated. Thus, even if there is brain injury in a typical whiplash patient with no loss of consciousness, brief dazed and confused interval and no retrograde amnesia, it must be at the lowest level of DA I. It would be impossible to account for the disabling severity reported by many chronic whiplash patients.

\section{Summary revisited and conclusions}

Patients with a whiplash injury frequently have cognitive symptoms. The general quality of the symptoms is quite consistent from patient to patient. The symptoms are very similar to patients who have "ding" injuries, i.e., grade 1 - the mildest
- concussions. The symptoms are also very similar, although less frequent and usually less marked, to those of patients with classic concussions. A small number of patients with whiplash have persistent cognitive complaints, but they are embedded in a much more complicated collection of somatic and psychological symptoms. To assign them primary neurological causation underestimates their multi-factorial basis.

$\mathrm{N}$ europsychological tests in whiplash patients frequently demonstrate deficits compatible with the symptoms. SPECT may demonstrate regional hypoperfusion consistent with the symptoms and the neuropsychological tests. For patients with classic concussions there is a reasonable congruence between resolution of symptoms, signs and SPECT changes. That chronological congruence has not been demonstrated in pure whiplash patients, but in chronically symptomatic whiplash patients, SPECT abnormalities are common. It is certainly possible that a fraction of patients with whiplash suffer transient brain dysfunction placing them at the mildest end of the concussion spectrum.

But the last question in the introduction asked if brain injury best accounts for the persisting cognitive symptoms after whiplash. In the absence of an unambiguous biological measure of persistent brain damage, the an swer is " $\mathrm{N} \mathrm{O".} \mathrm{Brain} \mathrm{injury}$ is an unsatisfactory explanation. The symptoms have absoluteIy DQ specificity for brain injury. The SPECT abnormalities are essentially uninterpretable given the enormous overlap with other, non-neurological disorders that are almost universal concurrent diagnoses in these patients. $\mathrm{N}$ europsychological testing only demonstrates that the patient is reporting his or her difficulties accurately; there are deficiencies on memory and attention tasks. This corroboration carries DQ useful conclusions about causation. When properly assessed, the patients frequently are underperforming due to pain, medication, depression, anxiety, sleep disruptions, stress or poor motivation. In the absence of a history of whiplash, the patients' symptoms, signs and SPECT/PET findings would be seen as parsimoniously and wholly accounted for by pain, medication, depression, anxiety, sleep disruptions, stress or poor motivation.

It is also the case that pain, medication, depression, anxiety, and sleep disruptions are potentially highly treatable although it is uncertain if that can be claimed for stress or poor motivation. If there is lingering neurological dysfunction and cognitive in efficiency, there are no validated direct treatments. Compen satory programs using calendars, PDA s, schedules free of un predictable interference, sleep hygiene and the like will surely help anyone but may require more effort than pain, medication, depression, anxiety, sleep disruptions, stress or poor motivation will allow. Endlessly hunting for proof of brain injury is clinically detrimental and draws focus and energy from treatment of the disorders that can actually be treated. Failure to treat the treatable will only increase anxiety and prolong disability. Should some agent - cholinesterase inhibitors, SSRI antidepressants, gingko, caffeine or something as yet undiscovered or not considered - be useful in treatment of forgetfulness, distractibility, and slow mental processing, it should, of course, be utilized, whether or not it can be proven to target a specific neural injury. We are waiting for that day. 


\section{REFERENCES}

1. CANTU RC. G uidelines for return to contact sports after a cerebral concussion. Physician Sports M edicine 1986; 14:75-83.

2. Q uality Standards Subcommittee A A N. Practice parameter: The management of concussion in sports. N eurology 1997; 48:581-585.

3. Ettlin T, Kischka U, Reichmann S, Radil EW, Heim S, W engen D, ET AL. C erebral symptoms after whiplash of the neck: a prospective clinical and neuropsychological study of whiplash injury. J N eurol N eurosurg Psychiatry 1992; 55:943-948

4. Radanov BP. Sturzenegger M, DeStefano G, Schnidrig A. Relationship between early somatic, radiological, cognitive and psychosocial findings and outcome during a one-year follow-up in 117 patients suffering from common whiplash. British Journal of Rheumatology 1994; 33:442-448.

5. SMED A. Cognitive function and distress after common whiplash. A cta N eurologica Scandanavia 1997: 95:73-80.

6. Karlsborg M, Smed A, Jespersen H, Stephensen S, Cortsen M, JENNUM P, ET AL. A prospective study of 39 patients with whiplash injury. A cta N eurologica Scandanavia 1997; 95:65-72.

7. KASCH H, BACH FW, JEN SEN TS. H andicap after acute whiplash injury: a 1-year prospective study of risk factors. N eurology 2001 56:1637-1643.

8. HenRy GK, Gross HS, Hemdon CA, Furst CJ. Nonimpact brain injury: neuropsychological and behavioral correlates with consideration of physiological findings. A pplied N europsychology 2000; 7:65-75

9. Keller M, Hiltbrunner B, Dill C, Kesselring J. Reversible neuropsychological deficits after mild traumatic brain injury. N eurol N eurosurg Psychiatry 2000; 68:761-764.

10. KischKa U, EtTlin T, Heim S, Schmid G. Cerebral symptoms following whiplash injury. European N eurology 1991; 31:136-140.

11. A LEXA N DER M P. M ild traumatic brain injury: Pathophysiology, natural history, and clinical management. N eurology 1995; 45:1253-1260.

12. Borchgrevink G, Smevik 0, HaAve I, Haraldseth 0, Nordby A, LEREIM I. M RI of cerebrum and cervical column within two days after whiplash neck sprain injury. Injury 1997; 28:331-335.

13. RONNEN HR, DE KORTE PJ, BRINK PR, VAN DER BIJL HJ, TONINO AJ, FRANKE CL. A cute whiplash injury: is there a role for M R imaging? a prospective study of 100 patients. Radiology 1996; 201:93-96.

14. RADANOV BP, BICIK I, DVORAK J, ANTINNES J, VON SCHULTHESS GK, BUCK A. Relation between neuropsychological and neuroimaging findings in patients with late whiplash syndrome. J N eurol N eurosurg Psychiatry 1999; 66:485-489.

15. Otte A, Ettlin T, Fierz L, Mueller-Brand J. Parieto-occipital hypoperfusion in late whiplash syndrome: first quantitative SPET study using technetium-99m bicisate (ECD). Eur J N ucl M ed 1996; 23:72-74.

16. Radanov BP, DiStefano G, Schnidrig A, Sturzenegger M, A U GUSTINY MA . Cognitive functioning after common whiplash: a controlled follow-up study. A rchives of N eurology 1993: 50:87-91.

17. Kessels RPC, Keyser A, Verhagen W IM, van LuijtelaAr ELjM. The whiplash syndrome: a psychophysiological and neuropsychological study towards attention. A cta N eurologica Scandanavia 1998; 97:188-193

18. TAylor A E, COX CA, Ma ILIS A. Persistent neuropsychological deficits following whiplash: evidence for chronic mild traumatic brain injury? A rchives of Physical Medicine and Rehabilitation 1996; 77:529-535.

19. Schmand B, Lindeboom J, Schagen S, Heijt R, Koene T, HAMBURGER HL. Cognitive complaints in patients after whiplash injury: the impact of malingering. J N eurol N eurosurg Psychiatry 1998: 64:339-343.

20. Kessels RPC, A leman A, Verhagen W im, van Luijtelaar Eljm. Cognitive functioning after whiplash injury: a meta-analysis. Journal of International N europsychological Society 2000; 6:271-278.

21. Gennarelli Ta, ThibaUltLe, adams JH, Graham DI, Thompson CJ, MARCINCIN RP. Diffuse axonal injury and traumatic coma in the primate. A nnals of N eurology 1982; 12:564-574.

22. O PPENHEIMER DR. M icroscopic lesions in the brain following head injury. I N eurol N eurosurg Psychiatry 1968; 31:299-306.

23. Radanov BP, DiStefano G, Schnidrig A, Sturzenegger M Common whiplash: psychosomatic or somatopsychic. J N eurol N eurosurg Psychiatry 1994; 57:486-490.
24. KING N S. Post-traumatic stress disorder and head injury as a dual diagnosis: "islands" of memory as a mechanism. J N eurol N eurosurg Psychiatry 1997; 62:82-84.

25. Moss-M orris R, Petrie KJ, Large RG, Kudd RR. $N$ europsychological deficits in chronic fatigue syndrome: artifact or reality. J N eurol N eurosurg Psychiatry 1996; 60:474-477.

26. MUFSON M, REGESTEIN QR. The spectrum of fibromyalgia disorders. A rthritis and R heumatism 1993; 36:647-650.

27. Buskila D, Neuman L, Vaisberg G, Alkalay D, W olfe F. Increased rate of fibromyal gia following cervical spine trauma: a controlled study of 161 cases of cervical spine injury. A rthritis and Rheumatology 1997; 40:446-452.

28. LeES-HALEY PR, BROWn RS. N europsychological complaint base rates of $\mathrm{70}$ personal injury claimants. A rchives of Clinical N europsychology 1993; 8:203-209.

29. LeES-H A LEY PR, DUNn JT. The ability of naive subjects to report symptoms of mild brain injury, post-traumatic stress disorder, major depression, and generalized anxiety disorder. Journal of Clinical Psychology 1994; 50:252-256.

30. Mittenberg W, Digiulio DV, Perrin S, Bass A E. Symptoms following mild head injury: expectations as aetiology. J N eurol N eurosurg Psychiatry 1992; 55:200-204.

31. Schrader H, Obelieniene D, Bovim G, Surkiene D, Mickeviciene D, M ISEVICIENE I, ET AL. N atural history of late whiplash syndrome outside the medicolegal context. Lancet 1996; 347:1207-1211.

32. LISHMAN WA. Physiogenesis and psychogenesis in the 'postconcussional syndrome'. British Journal of Psychiatry 1988; 153:460-469.

33. Bicik I, Radan ov BP, SchäferN, DVorak J, Blum B, Weber B, ET AL. PET with 18-fluorodeoxyglucose and hexamethylpropylene amine oxime SPECT in late whiplash syndrome. N eurology 1998; 51:345-350.

34. Masdeu JC, van Heertum Rl, Kleiman A, A nselmi G, Kissane K, HOM G J, ET A L. Early single-photon emission computed tomography in mild head trauma. Journal of N euroimaging 1994; 4:177-181.

35. Ja cobs A, PUt E, IngELS M, PUt T, Bossuyt A. One-year follow-up of technetium-99m-H M PA O A PECT in mild head injury. Journal of N uclear M edicine 1996; 37:1605-1609.

36. Gray BG, IChISE M, Chung D-G, Kirsch JC, Franks W. Technetium-99m-H M PA O SPECT in the evaluation of patients with remote history of traumatic brain injury: a comparison with $X$-ray computed tomography. J ournal of N uclear M edicine 1993; 33:52-58.

37. ICHISe M, ChUNG D-G, WANG P, W ORTZMAN G, GRAY BG, FRAN KS W. Technetium- 99m-H M P A O SPECT, CT and M RI in the evaluation of patients with chronic traumatic brain injury: a correlation with neuropsychological performance. Journal of $\mathrm{N}$ uclear Medicine 1994; 35:217-226.

38. Kant R, SMITH-SeEmiller L, ISAAC G, DUfFy J. TC-HM PA O SPECT in persistent post-concussion syndrome after mild head injury: comparison with M RI/CT. Brain Injury 1997; 11:115-124.

39. IIKADA T, NAKAJIMA T, SUZUKI Y, OKAZAKI A, MaEHARA T, SHIRAISHI H. Q uantitative regional cerebral flow measured by Tc-99 H M P A O SPECT in mood disorder. Psychiatry Research 1997: 68:143-154.

40. Ito H, Kawashima R, Awata S, Ono S, Sato K, Goto R, et al. $H$ ypoperfusion in the limbic system and prefrontal cortex in depression: SPECT with anatomic standardization technique. Journal of N uclear M edicine 1996;3 7:410-414.

41. GOODWIN GM. N europsychological and neuroimaging evidence for the involvement of the frontal lobes in depression. Journal of Psychopharmacology 1997; 11:115-122.

42. KENNEDY SH, JAVANMARD M VACCARIN O FJ. A review of functional neuroimaging in mood disorders: positron emission tomography and depression. C anadian Journal of Psychiatry 1997; 42:467-475.

43. Dolan RJ, Bench CJ, Brown RG, Scott LC, Frackowiak RS. Regional cerebral blood flow abnormalities in depressed patients with cognitive impairment. J N eurol N eurosurg Psychiatry 1992; 55:428-435.

44. Lucey N, Costa DC, A dihead G, Deahl M, Busatto G, GACIN OVIC S, ET AL. Brain blood flow in anxiety disorders: OCD panic disorder with agoraphobia, and post-traumatic stress disorder on 99mTCH M P A O single photon emission tomography (SPET). British Journal of Psychiatry 1997; 171:346-350.

This material was presented at the International C ongress on W hiplash A ssociated Disorders, Berne, Switzerland, M arch 8 to 10, 2001. The paper appeared originally in the book "W hiplash A ssociated Disorders" - medical, biomechanical and legal aspects, published by Staempfli Publishers Ltd, Berne 2002. The paper is published in N orth A merica in Pain Research \& M anagement with the permission of Staempfli Publishers Ltd. 


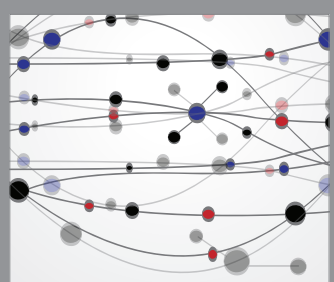

The Scientific World Journal
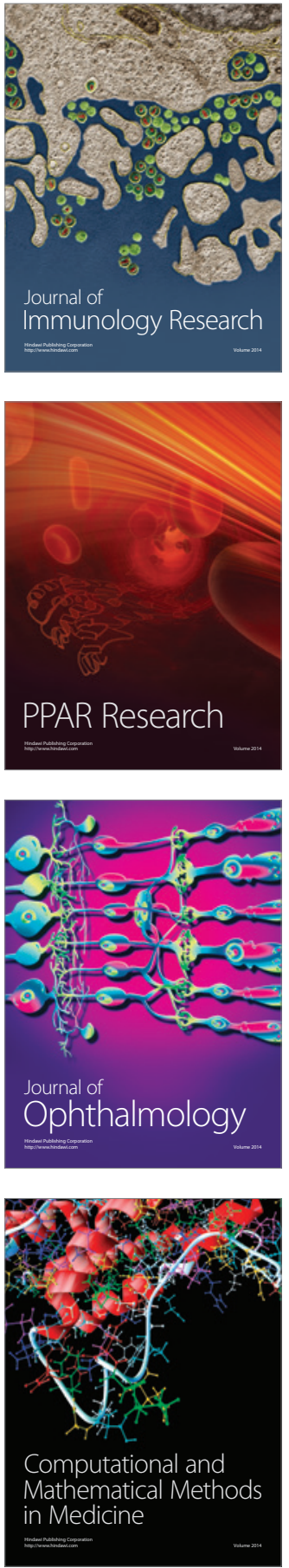

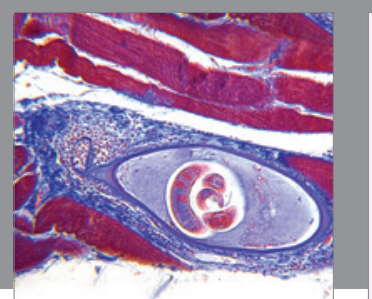

Gastroenterology Research and Practice

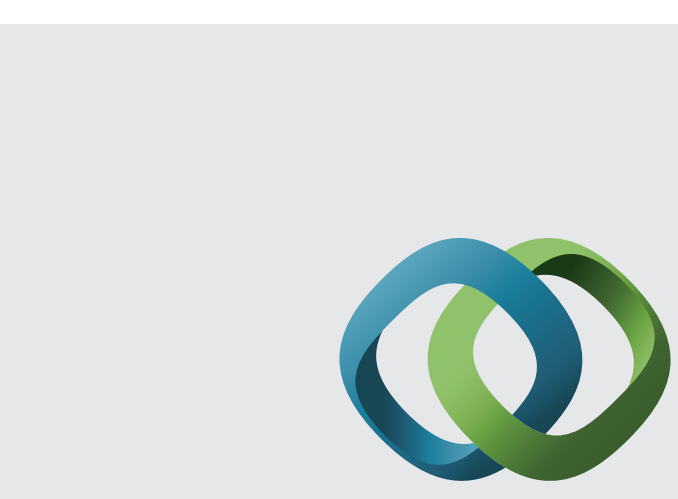

\section{Hindawi}

Submit your manuscripts at

http://www.hindawi.com
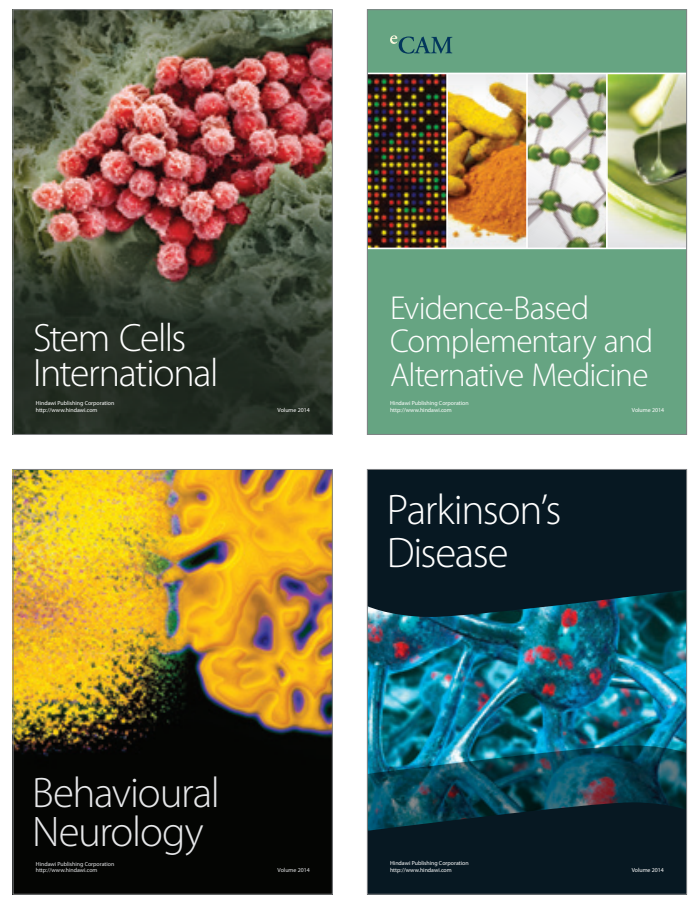
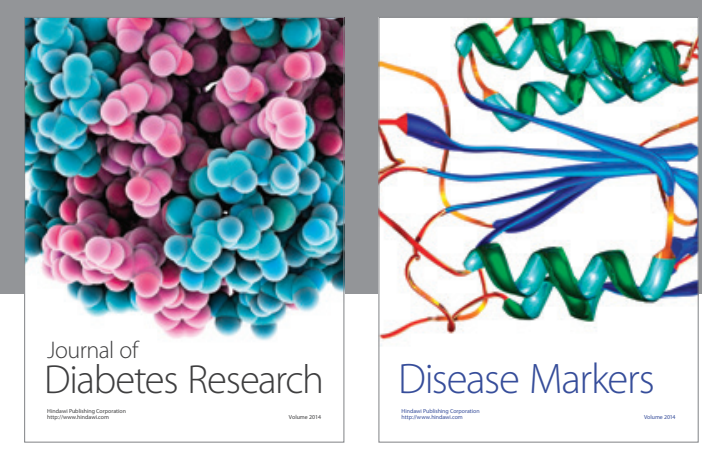

Disease Markers
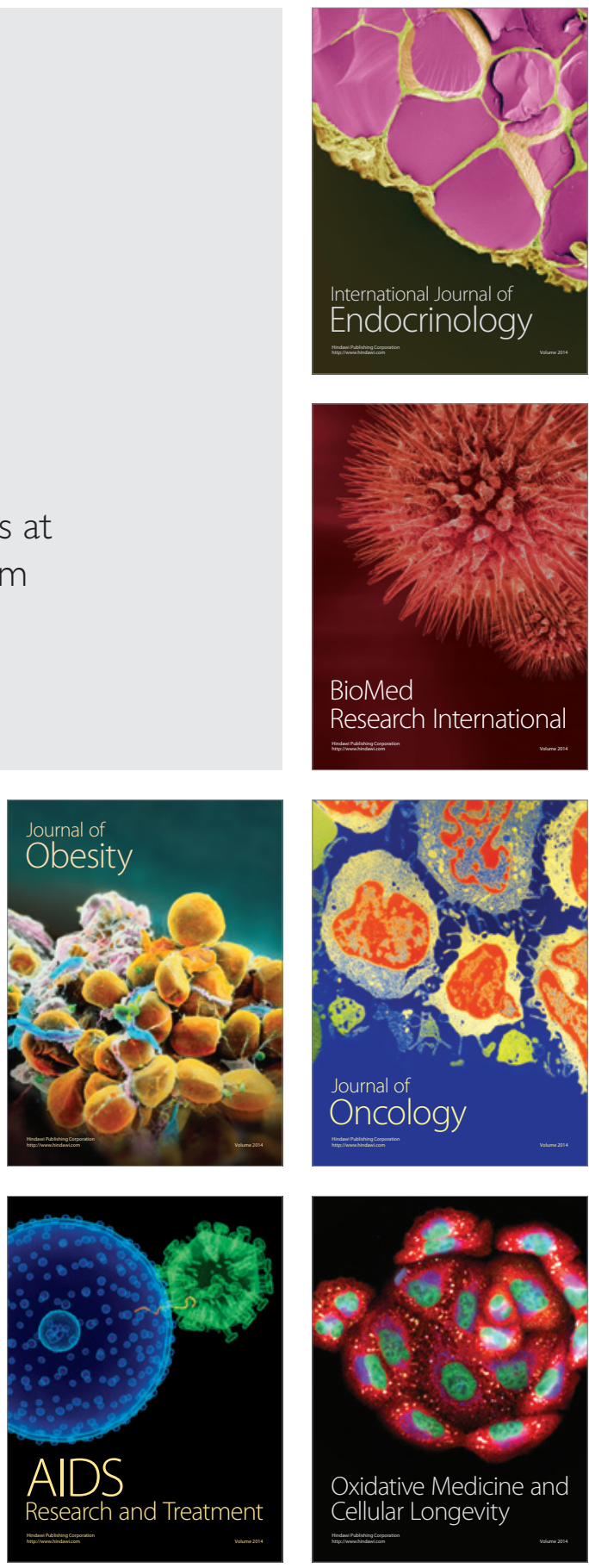